\title{
Produção de sentido de nacionalidade na minissérie Queridos Amigos
}

Maria Cristina Mungioli

\section{Resumo:}

Apresentamos algumas considerações e apontamentos introdutórios referentes a uma pesquisa em andamento em que nos propomos a analisar e discutir a produção de sentido na linguagem televisual e mais especificamente no gênero minissérie brasileira. A aproximação em relação aos objetivos de pesquisa será feita a partir da análise dos gêneros discursivos e temas presentes na minissérie Queridos Amigos. Buscamos compreender por meio dos discursos e temas dessa minissérie as inter-relações do circuito comunicação-cultura e suas implicações na elaboração de uma imagem de Brasil.

\section{Palavras Chave:}

Minissérie Queridos Amigos, produção de sentido, sentido de nacionalidade.

\begin{abstract}
:
In this article are presented some considerations and introductory notes relating to an ongoing study in which we propose to examine and discuss the production of meaning in televisual language and more specifically in the genre of Brazilian miniseries. The alignment with the goals of the research will be made from the analysis of discoursive genres and themes of the miniseries Queridos Amigos. We seek to understand through discourse and themes of the miniseries the interrelationships of the circuit culturecommunication and its implications in developing an image of Brazil.
\end{abstract}

\section{Keywords:}

TV series Queridos Amigos, meaning production, national feeling.

(...) quem somos nós, quem é cada um de nós senão uma combinatória de experiências, de informações, de leituras, de imaginações? Cada vida é uma enciclopédia, uma biblioteca, um inventário de objetos, uma amostragem de estilos, onde tudo pode ser remexido e reordenado de todas as maneiras possíveis

(Ítalo Calvino).

\section{Introdução}

Nosso objetivo, neste trabalho, é apresentar algumas considerações e apontamentos introdutórios referentes à pesquisa que estamos desenvolvendo em torno da questão da produção de sentido(s) de nacionalidade por meio das narrativas televisuais. Uma das etapas dessa pesquisa tem por objetivo estudar os discursos e os temas na minissérie Queridos Amigos exibida no ano de 2008 pela Rede Globo de Televisão. A escolha dessa minissérie para análise deveu-se aos temas "nacionais" abordados em sua trama: movimento estudantil de resistência à ditadura militar pós-64, exílio político dos opositores à ditadura, retorno de exilados, luta por eleições diretas. 
Em nossa análise, consideramos o gênero teledramatúrgico como lugar de memória (MOTTER, 20002001), como espaço de construção de significados e, por conseguinte, como uma das formas pelas quais se constitui(em) a(s) identidade(s) brasileira(s) que forja(m) os sentidos de uma nacionalidade. Vista dessa perspectiva, a força do gênero na construção de significados não se limita às imagens e aos discursos veiculados pela tela de TV, mas também a todo um universo discursivo que a eles se referem e no qual se podem observar as lutas ideológicas, os interesses econômicos. Enfim, um universo no qual ocorre a luta pela hegemonia e no qual é possível observar a linguagem não apenas como forma de comunicação, mas como elemento (en)formador da consciência e dos discursos, pois é por meio dos discursos que nos constituímos como pessoas e nos situamos no mundo para transformá-lo, para agir sobre ele (BAKHTIN, 2002)

\section{Teledramaturgia, Discursos e Sentidos de Nacionalidade}

A primeira minissérie brasileira (1), Lampião e Maria Bonita (2), foi ao ar em 1982 e desde então esse gênero tem acompanhado os brasileiros compondo um vasto painel de temas que se desdobram em tramas urbanas e regionais que possuem como ponto comum a busca de "fotografar" a heterogeneidade constitutiva da "alma brasileira" e da nação. Nessa fotografia, há lugar para personagens que se constroem entre dramas pessoais, amores impossíveis e destinos trágicos, mas há lugar também para a escrita ou reescrita de momentos importantes para a constituição da nação. Esse gênero, cuja longevidade atesta sua apreciação pelo público, tem construído sentidos de povo e de nação por meio de narrativas que se alimentam em dois eixos considerados típicos da produção ficcional brasileira, pensada aqui não apenas em termos de televisão, mas também de literatura: o romance de costumes e o nacionalismo (3).

Antonio Cândido $(1965,2002)$ considera essas duas características desenvolvidas na prosa a partir do Romantismo como constituintes de um modo de escrever brasileiro em que as marcas da oralidade se fazem presentes por meio de mecanismos de estruturação (texto propicio à leitura em voz alta) e de abordagem temática (o nacionalismo, os costumes, o cotidiano). Segundo o crítico, dessa forma, construiu-se um estilo brasileiro de narrar que apela para a emoção e que, calcado na oralidade, solicita mais da audição que da habilidade decifrar letras (4). Um estilo que formou um público acostumado a narrativas cujos temas tratados enfatizavam (e enfatizam) a "realidade" local, a "cor local" (Cândido, 1965: 96). Essas características se revestem de interesse para o estudioso das minisséries principalmente por que quase $60 \%$ dos roteiros dessas produções são baseados em obras literárias nacionais.

As duas características da literatura nacional anteriormente mencionadas também podem ser aplicadas às telenovelas e às minisséries em cujas tramas são abordados temas relevantes (e outros nem tanto) que perpassam o cotidiano de nossa população. Manifestam-se no cotidiano ficcional as diferenças sociais, as peripécias de pessoas das várias camadas sociais que se equilibram no fio da navalha entre o bom e o mau caminho; ou ainda, a corrupção instalada no país nos mais diferentes níveis e instituições. É nessa busca pela verossimilhança que a telenovela e a minissérie brasileiras podem ser vistas como retratos do Brasil, pois, embora fragmentadas e multiformes, essas narrativas contêm elementos de análise, de compreensão e de síntese da identidade brasileira. Portanto, sua importância como produto cultural decorre não apenas de sua penetração nas diversas camadas da sociedade brasileira, mas também do tratamento discursivo, temático e estético que lhe são característicos e que, para muitos, são responsáveis por sua grande audiência. Tratamentos esses que se revelam na constituição da inter-relação entre ficção e cotidiano que Motter (2000-2001: 76) destaca como característica própria da telenovela brasileira:

Se o fio melodramático condutor da história, o apelo à emoção, o caráter de serialidade e duração a situam no espaço da novela, o compromisso social, um modo peculiar de estruturação do cotidiano e a incompletude - que lhe permite manter com o telespectador um diálogo vivo configuram um fazer próprio, aprimorado e em permanente renovação que individualiza a 
telenovela como produção genuinamente brasileira.

Assim, estabelecendo uma vigorosa relação entre ficção, cotidiano e realidade, a teledramaturgia oferece ao espectador uma forma ver o mundo e de ver-se no mundo por meio de um tratamento estético e temático em que as cores e as dores do Brasil se revelam tanto pela presença quanto pela ausência.

Dentro desse quadro, é possível compreender as narrativas literárias ou televisuais como espaços de produção de sentidos de nacionalidade na medida em que constroem/desconstroem discursos acerca de valores, sentimentos, ideias e possibilitam às populações a criação/manutenção de referenciais comuns que formariam o que Bhaba (2003) denominou - para definir o conceito de nacionalidade - “(...) uma forma de afiliação social e textual (...)" (BHABHA, 2003: 199).

Segundo o pensador indiano, para compreendermos a nacionalidade e o nacionalismo é preciso termos em mente a noção de localidade da cultura, uma localidade que não encontra referência apenas no mundo "real", mas principalmente num conjunto de sentimentos que emerge nas relações humanas, principalmente naquelas em que a narrativa da nação surge como força aglutinadora, como metáfora da própria nação.

De acordo com Bhabha (2003: 206), o conceito de povo não se constrói apenas pela reiteração dos "eventos históricos" ou dos "componentes de um corpo político patriótico", mas principalmente por "uma complexa estratégia retórica de referência social”. Dentro desse quadro, surge:

(...) um território conceitual disputado, onde o povo tem de ser pensado num tempo-duplo; o povo consiste em "objetos" históricos de uma pedagogia nacionalista, que atribui ao discurso uma autoridade que se baseia no preestabelecido ou na origem histórica constituída no passado, o povo consiste também "sujeitos" de um processo de significação que deve obliterar qualquer presença anterior ou originária do povo-nação para demonstrar os princípios prodigiosos, vivos do povo como contemporaneidade, como aquele signo do presente através do qual a vida nacional é redimida e reiterada como um processo reprodutivo (BHABHA, 2003: 206-207)

Instaura-se, assim, um movimento de constante produção de sentidos por meio de discursos que atualizam fatos históricos, que os ressignificam por meio de novas instâncias enunciativas constituindo novos enunciadores-enunciatários potencializados pela atualização - ou seja, a instauração do tempo duplo ao qual se refere Bhabha. Dito de outra forma, é preciso que se encontrem no discurso do passado significados que façam sentido no presente, que digam alguma coisa aos sujeitos do presente.

\section{Minisséries, Gêneros e Construção de Sentidos de Nacionalidade}

Consideradas o produto mais bem acabado da teledramaturgia brasileira(5), as minisséries se constituíram ao longo dos anos em estrelas de primeira grandeza no universo televisual brasileiro. Um pouco mais protegidas do ritmo acelerado da produção industrial das telenovelas (BALOGH, 2004), as minisséries são fruto de longa pesquisa prévia de seus idealizadores. Além disso, essa característica também permite que sejam mais bem cuidadas todas as etapas de produção o que acaba conferindo à minissérie uma qualidade técnica e narrativa superior à maioria dos outros produtos televisuais.

Estruturalmente, as minisséries brasileiras descendem da telenovela (Pallottini, 1998) e sua característica principal é ter como ponto de partida um "texto fechado" e, por isso, possuem desde o início das gravações o desenvolvimento da trama e seu desenlace previstos. Isso faz com que tramas e personagens possuam uma linha de desenvolvimento bem delineada, o que permite ao autor, diretor e elenco de atores 
uma exploração mais profunda das situações dramáticas.

É também o fechamento do texto que possibilita ao diretor um tratamento estético e um acabamento temático mais refinado, pois não está trabalhando com um texto em construção cujo desenvolvimento exato ele ignora (como muitas vezes acontece na telenovela) (6). Em termos de duração, as minisséries brasileiras variam muito, podem ter entre 5 e 40 capítulos.

Além disso, é preciso enfatizar que não apenas os roteiros das minisséries, mas também o desenvolvimento da idéia e o trabalho de pesquisa têm ficado sob responsabilidade de autores do primeiro time da emissora que contam com o trabalho de diretores e elencos não menos talentosos. Soma-se a isso uma cuidadosa seleção de temas e de obras de reconhecido valor estético e social. Essa conjunção de fatores tem sido fundamental para elaboração de produções ficcionais de qualidade que se diferenciam no panorama televisual brasileiro, embora nem sempre isso signifique a liderança em termos de audiência.

Ao longo de 27 anos, a Rede Globo de Televisão exibiu 65 minisséries(7). Produção apurada, roteiros bem cuidados e direção competente e muitas vezes inovadora conferiram a algumas dessas produções um lugar privilegiado no cenário televisual brasileiro. Um lugar identificado como propício não apenas para a consolidação de uma imagem de marca de qualidade da rede de televisão que as produziu, mas também para a criação/recriação de obras que se identificam com a constituição do Brasil como nação.

Apenas a título de exemplo do uso de uma espécie de mecanismo de legitimação, reproduzimos aqui trechos de uma publicidade de três páginas inteiras veiculada nos principais jornais do país (8). Na primeira página, há um texto em que a Rede Globo valoriza o papel da TV aberta no país:

A última palavra em TV aberta no Brasil são duas: "muito obrigado"

(...) A TV aberta tem uma importância na vida dos brasileiros sem paralelo em outros países. Um dos motivos é que a sua programação espelha a brasilidade, integrando o país e valorizando a cultura e o talento nacionais. Hoje a TV aberta chega a 99\% do nosso território e é o principal meio de informação e entretenimento, servindo de importante complemento à educação formal.

As duas páginas seguintes são ocupadas por uma foto colorida de Flora e Donatella (Patrícia Pillar e Cláudia Raia, respectivamente), as duas protagonistas da telenovela $A$ Favorita, que se superpõem a imagens em preto e branco de outras obras de ficção da emissora. O texto que acompanha essas imagens retoma a idéia de liderança, de qualidade e de credibilidade:

A Favorita: $66 \%$ de telespectadores, $100 \%$ de liderança.

Pode escolher o horário, o público ou a região: a Globo é sempre líder. (...)E se a liderança da Globo é tão forte, é porque se constrói todos os dias, com respeito e credibilidade. Até porque, antes de conquistar a liderança a gente precisa conquistar a sua confiança.

Dentro desse quadro, as minisséries ocupam lugar de destaque, pois atuam nos dois sentidos consolidação de imagem de marca e identificação com os valores da cultura nacional - e confirmam, segundo a própria emissora anuncia, não apenas sua condição de líder de audiência, mas também de emissora socialmente responsável.

Entretanto, é preciso que se analisem as produções televisuais, sobretudo as ficcionais, não apenas sob o prisma das relações econômicas ou mercadológicas. Martin-Barbero (2001) argumenta que é preciso que se tenha em mente o potencial do gênero no qual/pelo qual se constituem mediações que o configuram 
como matriz cultural.

Para Martín-Barbero (2001: 211), “(...) o gênero não é somente qualidade da narrativa, e sim o mecanismo a partir do qual se obtém o reconhecimento - enquanto chave de leitura, de decifração do sentido, e enquanto reencontro com um "mundo" (...)." (aspas do autor). Reencontro que se organiza cultural e cognitivamente por meio das relações inerentes ao sistema de comunicação estabelecido pela sociedade. Nessa perspectiva, o gênero organiza o mundo na medida em que é por meio dele que se interpretam as narrativas que dão sentido às relações humanas. Em outras palavras, a noção de gênero determinará, de certa forma, um "modelo de escritura" (TODOROV, 1980: 49) e um "modelo de leitura". Ou seja, é o acabamento genérico e o conhecimento que o leitor possui do gênero que permitirá a compreensão de um determinado texto.

O conhecimento do gênero de uma produção televisual proporciona ao telespectador possibilidades de leitura e compreensão da obra artística. Entretanto, a própria definição do gênero a que pertence uma obra geralmente não lhe é dada de maneira intrínseca(9), ao contrário, há uma série de elementos paratextuais (entrevistas a jornais, revistas, emissoras de rádio e TV, chamadas de apresentação efetuadas pela emissora, outros programas da grade de programação da emissora) que se constituem como mediações e operam de maneira cognitiva - e por que não dizer também afetiva - no sentido de construir um conhecimento de gênero e de mundo dentro do qual é possível interpretar/reinterpretar as narrativas e de se situar frente aos temas e discursos que as constituem.

É com base nesse quadro que analisamos o fato de as minisséries brasileiras terem sido consideradas o formato preferencial para veicular histórias às quais são atribuídas uma função comemorativa em relação a datas nacionais ou a datas importantes para a emissora. Em 1985, Grande Sertão: Veredas(10), O tempo e o vento(11) e Tenda dos Milagres(12) foram exibidas como parte da comemoração dos 20 anos de Rede Globo. Em 1988, a minissérie Abolição(13) foi apresentada como comemorativa da Abolição da Escravatura, no ano seguinte República(14) celebrou o centenário da proclamação da república. Esse tipo de iniciativa de mostrar o Brasil e a história do Brasil aos telespectadores se manteve firme nos anos seguintes. Em 2000, houve minisséries que procuraram mostrar a chegada dos portugueses ao Brasil ( $A$ invenção do Brasil(15)) e a luta dos portugueses e paulistas pelo domínio de terras e dos índios $(A$ Muralha(16)).

A preocupação em mostrar, forjar ou mesmo, como alguns dizem, resgatar os valores identitários da nação brasileira continua mobilizando alguns diretores. É o que se depreende, por exemplo, das palavras de Luiz Fernando Carvalho constantes em entrevista concedida, em 2005, a Leila Reis a propósito da minissérie Hoje é dia de Maria; o próprio título da matéria não deixa dúvidas: A brasilidade é o único tema de Luiz Fernando Carvalho (17). Em resposta à pergunta sobre que Brasil queria representar na TV, o diretor afirmou: "Um Brasil que, apesar dos problemas, das injustiças ainda sonha. Não é um sonho puro e simples, mas um sonho que nos ajuda a despertar. A função da arte é despertar as pessoas. Aí eu não separo por categorias, é função da TV, do cinema, do teatro." E, na resposta sobre o que pretendia com produções como Hoje é dia de Maria, ele retoma a idéia mais explicitamente: "Atravessar fronteiras da cultura nordestina, em termos de quilômetros é fazer uma viagem maior que o continente. Quero retratar uma brasilidade sem regionalismos porque eles inevitavelmente acabam caindo nos clichês."

Evidencia-se, portanto, por meio de suas palavras que a análise pura e simples do uso das minisséries e das telenovelas como estratégias ou formatos industriais não dão conta da multiplicidade de discursos e sentidos que elas constroem na constituição de uma espécie de missão que alguns diretores e autores (18) com relação a sua função social. 


\section{Tema}

A fundamentação teórica que subsidiará nossa análise dos temas nas minisséries está presente na obra de dois grandes teóricos da linguagem Bakhtin e Tomachevski (19).

Para Bakhtin (2002), é o tema que dá o acabamento específico a um enunciado concreto considerado como unidade da comunicação verbal; o tema é o responsável pela compreensão que fazemos de um enunciado como um todo. Para desenvolver esse conceito, o autor apresenta a distinção entre significação e tema. A significação de um enunciado está ligada ao sentido que se constrói a partir da compreensão dos elementos da língua, das palavras. Porém, essa significação é provisória, parcial, inacabada, uma vez que é reiterável e idêntica a uma infinidade de enunciados. Já o tema, é "individual e não reiterável" (BAKHTIN, 2002: 128) uma vez que “(...) se apresenta como a expressão de uma situação histórica concreta que deu origem à enunciação" (BAKHTIN, 2002: 128). Portanto, o acabamento temático de um enunciado está intrinsecamente ligado à situação histórica concreta em que o mesmo ocorre. Dessa maneira, a compreensão "completa" de um enunciado se faz por meio do tema que se constrói nas interações humanas.

A televisão, devido a suas características peculiares, usa e abusa do caráter fragmentado e provisório contido na atualidade do cotidiano, acompanha-a na sua fragmentação e oferece-a para degustação de seus telespectadores em doses diárias e em horário certo por meio de formatos seriados. É o tratamento temático que articula os programas de televisão à realidade cotidiana e à realidade histórica que envolve os telespectadores. Porém, Tomachevski (1976: 172) adverte que em literatura (e em televisão, diríamos nós):

Não é suficiente escolher um tema interessante. É preciso sustentar o interesse, estimular a atenção do leitor. O interesse atrai, a atenção retém. O elemento emocional contribui muito para cativar a atenção. Não é sem razão que, segundo sua característica, classificam-se em comédias e tragédias as peças destinadas a agir diretamente sobre um grande público.

Além de um tema interessante é necessário que a trama sustente a atenção do leitor/telespectador, essa sustentação se organizará em torno das emoções suscitadas pelas situações vividas pelas personagens cujas atitudes, sonhos, desejos serão objeto de simpatia ou antipatia por parte do público. Tomachevski (1976: 172) lembra que “(...) o elemento emocional encontra-se na obra, que não é introduzido pelo leitor". Dessa forma, o tema desenvolvido de maneira a provocar a emoção do leitor será responsável pela atenção e interesse que o mesmo dedica à obra literária, ou, em nosso caso, à ficção televisual. Mesmo esse elemento emocional não escapa ao contexto da situação sócio-histórica de quem lê um livro ou assiste a um programa de televisão. Histórias e imagens que poderiam ser chocantes ou desagradáveis para nossos antepassados não mais o são para nós (ou vice-versa). Para compreendermos essa situação, é preciso que retomemos a noção de tema desenvolvida por Bakhtin (2002: 129) em relação ao enunciado, segundo a qual "tema é um sistema de signos dinâmico e complexo" e que este sistema é eminentemente construtor e construto da complexidade com que se tecem as relações de linguagem dentro das sociedades.

\section{Minissérie Queridos Amigos e Produção de Sentido}

Queridos Amigos foi a sexta minissérie escrita por Maria Adelaide Amaral e contou em 25 capítulos (de 18.02 a 28.03.2008) (20) a história do reencontro de um grupo de nove amigos (21) em 1989 após anos de separação. O roteiro teve como base próprio livro da autora Aos meus amigos cujo lançamento data de 1992. (22) Apresentada pela imprensa e pela própria autora como uma narrativa em que se mesclam fatos de sua vida e de ficção (23), a minissérie mostra o esforço de um dos integrantes do grupo, Leo, (Dan 
Stulbach) em aproximar os amigos que enfrentaram juntos os chamados "anos de chumbo" (24). Anos marcados pela ação repressora dos governos militares contra militantes de esquerda.

O reencontro ocorre em meio à constatação de que muito do que se havia sonhado, planejado, construído desabara ou estava desabando, tanto no plano pessoal quanto no plano político nacional e internacional. No cenário nacional, a minissérie retrata a eleição de Fernando Collor e, no internacional, a queda do Muro de Berlim e suas consequências não apenas na geopolítica internacional como também na mentalidade das pessoas que viveram a Guerra Fria e lutaram nos movimentos estudantis de 1968. Esse é o caso de boa parte dos amigos cujas vidas foram marcadas pela violência sofrida direta ou indiretamente em razão de suas convicções políticas contrárias ao regime militar instalado no Brasil pós-64. No plano econômico, a inflação e a dívida externa brasileiras são assuntos recorrentes na trama que mostra ainda de maneira crítica o cenário editorial brasileiro da década de 1980.

O passado aflora por meio do relato verbal dos fatos e também por meio de uma narrativa fílmica paralela a que os amigos assistem (25), na casa de Leo, no primeiro reencontro do grupo após muitos anos. Comentários saudosos do relacionamento fraterno do grupo que se autodenominava "família" são entremeados por palavras mais ácidas que dão a dimensão de que os amigos guardam ressentimentos e mágoas.

As relações entre os amigos, outrora marcadas pelo afeto e companheirismo, ganham tons sombrios em que o ressentimento e a constatação de que o mundo transformou alguns amigos jovens e lutadores em pessoas de meia-idade "mal resolvidas" no plano pessoal e profissional se corporificam e opõem os antigos companheiros. Ao mesmo tempo, o reencontro possibilita a cada um deles o redescobrimento de si mesmo e dos sentimentos que permearam amizades tão profundas. Esse duplo reencontro, consigo mesmos como indivíduos e como seres sociais (26), é operado pelo repensar e pelo redimensionamento de valores e sentimentos como amizade e solidariedade colocados em xeque diante da imponderabilidade da morte (ou do suicídio). Valores e sentimentos que se constroem pelos discursos e ações e que se consolidam como interdiscurso (27) materializado no tratamento temático que permeia a minissérie. É preciso enfatizar que esses discursos cronologicamente situados no passado constroem o presente, uma vez que, como lembra Motter (2001: 43), "a linguagem que articula e sustenta a memória, já por si só inoculadora de valores institucionais, é modelada para reelaborar o passado através do presente."

É justamente sobre a construção desse passado reelaborado pelo presente por meio de discursos e da criação de “(...) uma forma de afiliação social e textual (...)" (BHABHA, 2003: 199) como constituinte (e instituinte) da nacionalidade que pretendemos esboçar a análise de uma sequência da minissérie que nos parece bastante elucidativa do tempo duplo a que se referiu Bhabha (2003).

A sequência começa quando todos os amigos, exceto Vânia, estão na sala e Leo coloca no vídeo-cassete a fita em que está registrada a volta de Tito (Matheus Nachtergaele) e Vânia (Drica Moraes). A música que acompanha a sequência é $O$ bêbado e a Equilibrista, de João Bosco e Aldir Blanc, interpretada por Elis Regina. Os amigos assistem emocionados às cenas que mostram a chegada dos exilados políticos em 1979 (embaixo da tela há a legenda: 1979 - A volta dos exilados). Surgem na tela personagens da minissérie e exilados "reais" descendo do avião e sendo recebidos por familiares, amigos e correligionários. Entre os exilados, destacam-se Luiz Carlos Prestes, Miguel Arraes e Betinho. Vemos uma entrevista rápida de Betinho e, em seguida, Henfil fala ainda no aeroporto sobre a chegada dos exsobre a emoção do retorno de seu irmão ao país: "[a emoção] significa que a gente finalmente conseguiu trazer o Brasil para o Brasil. (...) E a emoção que ele deve estar sentindo é estranha; [é estranho] o que acontece no Brasil: as pessoas se emocionarem pelo fato de os brasileiros voltarem ao Brasil". 
Em seguida, as imagens continuam mostrando a volta dos exilados quando Vânia entra na sala e discute com Tito, seu ex-marido, que se diz ainda comunista e revolucionário. Ela diz que não acredita mais "em palavras de ordem, mas em arregaçar as mangas e ajudar o próximo". Depois de breve e intensa discussão, saindo da sala, acompanhada de seu marido (um empresário bem sucedido), Vânia diz a Tito: "O dia em que você chegar ao poder eu mudo para Miami". E ele lhe responde: "Você já está em Miami".

Numa primeira aproximação feita com a intenção de colocar alguns elementos para discussão, pode-se dizer que temos, nessas sequências, o confronto de ideologias permeado por rancores de uma relação amorosa desfeita e que ainda faz sofrer o ex-casal. Porém, na verdade o que está em jogo são dois tempos, duas realidades historicamente construídas e, por isso mesmo, dependentes de explicação. As realidades estão colocadas nas vozes das personagens: Tito remete ao passado em que as lutas em defesa de uma ideologia, em defesa do socialismo no Brasil faziam sentido. E Vânia, representando o presente, a desilusão a aceitação de que o que resta "é ajudar o próximo" e, se possível viver em Miami. Não são apenas duas personagens que se confrontam, mas sim duas ideologias antagônicas que manifestam por meio da emoção, do sentimento.

Podemos dizer que, muito mais do que as palavras, é todo o enunciado que significa matizado pela tematização. Um enunciado cujo discurso se constrói em relação não apenas ao todo discursivo da minissérie, mas em relação ao interdiscurso, à memória discursiva que torna possível nos compreendermos como sujeitos de um processo de significação (BAKHTIN, 2002) e como seres históricos. Há diversos elementos que contribuem para essa compreensão: a letra da música, os exilados "reais", os diálogos marcados não apenas pela emoção, mas também pelas ideologias. Instaura-se o tempo duplo (BHABHA, 2003), por meio do qual é possível que os fatos do passado da nação façam sentido no presente, que ganhem significação e se tornem parte do presente e constituam parte integrante do povo que constitui uma nação.

\section{Considerações Finais}

De certa forma, a minissérie produz um sentido de nacionalidade que se constrói pela heterogeneidade, pelo confronto de ideologias, pela aceitação/negação de um passado que insiste em ressurgir e clama por explicações. Explicações que se transformam em temas que surgem nas imagens da tela de televisão e pela boca de personagens que possuem ideologias e ... sonhos, que se emocionam e que emocionam o público; transmitindo-lhe muito mais que palavras, ou um discurso pedagógico. Constroem-se sentidos dimensionados pelo gênero teledramatúrgico como lugar de memória e como espaço de significação.

\section{Bibliografia:}

BHABHA, H. K. O local da cultura. Belo Horizonte: Ed. UFMG, 2003.

BAKHTIN, M. Estética da Criação Verbal. São Paulo: Martins Fontes, 2003. São Paulo: 2003.

BAKHTIN, M. Marxismo e filosofia da linguagem. São Paulo: Hucitec, 2002.

BALOGH, A. M. O discurso ficcional na TV: sedução e sonho em doses

homeopáticas. São Paulo: Editora da Universidade de São, 2002 (Acadêmica ; 44)

Calvino, Í. Seis propostas para o próximo milênio. São Paulo: Companhia das Letras, 1990. 
CANDIDO, A. Literatura e Sociedade. São Paulo: Cia. Editora Nacional, 1965.

CANDIDO, A. O romantismo no Brasil. São Paulo: Humanitas/FFLCH/SP, 2002.

DICIONÁRIO DA TV GLOBO Vol. 1: Programas de dramaturgia \& entretenimento. Projeto Memória das Organizações Globo. Rio de Janeiro: Jorge Zahar Ed., 2003.

JAUSS, H. R. Pour une esthétique de la réception. Paris: Gallimard. 2005.

MACHADO, A. A televisão levada a sério. 3ª ed. São Paulo: Editora Senac São Paulo, 2003.

MEMORIA GLOBO. Autores: histórias da teledramaturgia, livro 2. São Paulo: Globo, 2008.

MOTTER, M. L. Ficção e história: imprensa e construção da realidade. São Paulo: Arte \& CiênciaVillipress, 2001.

MOTTER, M. L. Telenovela: documento histórico e lugar de memória. Revista USP, São Paulo, n. 48. p. 74-87, dezembro/fevereiro 200-2001.

MUNGIOLI, M. C. P. Minissérie Grande Sertão: Veredas: gêneros e temas construindo um sentido identitário de nação. Tese de doutorado apresentada à ECA-USP. 2006.

ORLANDI, E. P. Análise de discurso: princípios e procedimentos. Campinas/SP: Pontes, 1999.

PALLOTTINI, R. Dramaturgia de televisão.São Paulo: Moderna, 1998.

SCHNAIDERMAN, B. Prefácio. In: Toledo, Dionísio de Oliveira (org) Teoria da literatura: formalistas russos. Porto Alegre: Globo, 1976.

TODOROV, T. Os gêneros do discurso. São Paulo: Martins Fontes, 1980.

TOLEDO, D. de O. (org). Teoria da literatura: formalistas russos. Porto Alegre: Globo, 1976.

TOMACHEVSKI, B. Temática. In: Toledo, Dionísio de Oliveira (org) Teoria da literatura: formalistas russos. Porto Alegre: Globo, 1976.

\section{Notas:}

(1) Neste texto, sempre que nos referirmos às minisséries brasileiras, estaremos nos referindo às minisséries produzidas e exibidas pela Rede Globo de Televisão.

(2) Escrita por Aguinaldo Silva e Doc Comparato, exibida de 26.04 a 05.05.1982, com 8 capítulos. Direção de Paulo Afonso Grisolli e Luís Antonio Piá.

(3) Cf. Antonio Cândido, Literatura e Sociedade e O romantismo no Brasil.

(4) Sobre a prevalência da oralidade na TV ver A. Machado, A televisão levada a sério. 
(5) Cf. Anna Maria Balogh. O discurso ficcional na TV: sedução e sonho em doses homeopáticas.

(6) Nota-se, portanto, a indissolúvel relação, que existe em toda obra de arte, entre forma e conteúdo. Cf. Mikhail Bakhtin, Estética da criação verbal.

(7) Somente nos anos de 1987, 1996 e 1997 não foi produzida nenhuma minissérie.

(8) Os trechos aqui comentados foram publicados no jornal O Estado de S. Paulo, $1^{\circ}$. Caderno, p. A15A17, de 08.10.2008.

(9) Cf. Hans Robert Jauss, Pour une esthétique de la réception.

(10) A minissérie em 25 episódios, de 18.11 a 20.12.1985, adaptação de Walter George Durst do romance Grande Sertão: Veredas, de Guimarães Rosa. O roteiro final e a direção foram de Walter Avancini.

(11) O tempo e o vento minissérie adaptada da obra homônima de Érico Veríssimo Foi levada ao ar de 22.04 a 31.05.1985 e teve 25 capítulos. Escrita por Doc Comparato. Direção geral de Paulo José.

(12) Escrita por Aguinaldo Silva e Regina Braga, baseada na obra homônima de Jorge Amado, direção de Paulo Afonso Grisoli, levada ao ar de 29.07 a 06.09.1985, com 30 capítulos.

(13) Escrita por Wilson Aguiar, com a colaboração de Joel Rufino dos Santos, roteiro e direção de Walter Avancini; foi levada ao ar de 22 a 25.11.1988.

(14) Escrita por Wilson Aguiar, com roteiro dele e de Walter Avancini e direção geral de Walter Avancini foi exibida de 14 a 17.11.1989. (DG: 330)

(15) Foi ao ar de 19 a 21.04.2000. Escrita e dirigida por Guel Arraes e Jorge Furtado, produzida pelo Núcleo Guel Arraes. A minissérie foi transformada em filme com o nome de Caramuru, a invenção do Brasil.

(16) Escrita por Maria Adelaide Amarale João Emanuel Carneiro, inspirada no livro homônimo de Dinah Silveira de Queiroz. Direção de Carlos Araújo e Luís Henrique Rios. Supervisão geral de Denise Saraceni e Daniel Filho

(17) Entrevista publicada no jornal O Estado de S. Paulo, de 14.01.2005, Caderno 2, p. D10.

(18) Exploramos esse tema mais profundamente em nossa tese de doutorado: Minissérie Grande Sertão: Veredas: gêneros e temas construindo um sentido identitário de nação.

(19) Como se sabe a teoria de Bakhtin opõe-se em diversos aspectos aos preceitos defendidos pelo grupo da Universidade de Moscou. A principal discordância entre eles estaria relacionada ao fato de que para os Formalistas o que importa é “(...) a literariedade, isto é, aquilo que torna determinada obra uma obra literária." (Jakobson apud Schnaidermann 1976: X). Essa conceituação promove uma espécie de cisão entre discurso literário e discurso "da vida", com a prevalência do primeiro sobre o segundo. Havia nesse movimento uma "herança mecanicista" (Jakobson apud Schnaidermann 1976: XIII) com a qual Bakhtin não concordava, porém a noção de tema de Tomacheski prevê uma certa interlocução entre autor e leitor. Tal noção também é o ponto de partida da análise que se estrutura basicamente nos usos que Bakhtin (2005) faz desse conceito quando analisou a obra de Dostoiévski. Daí a nossa opção por trabalhar com os 
dois teóricos.

(20) A direção geral da minissérie foi de Denise Saraceni responsável também pela direção da primeira minissérie escrita por Maria Adelaide Amaral em 2002, A Muralha.

(21) O grupo de amigos é formado por Lena (Débora Bloch), Ivan (Luiz Carlos Vasconcelos), Bia (Denise Fraga), Pedro (Bruno Garcia), Benny (Guilherme Weber), Tito (Matheus Nachtergaele), Vânia (Drica Moraes), Raquel (Maria Luisa Mendonça), Pingo (Joelson Medeiros), Lúcia (Malu Galli), Rui (Tarcísio Filho) e Leo (Dan Stulbach).

(22) Paralelamente à minissérie Queridos Amigos, a Editora Globo relançou o livro Aos Amigos.

(23) Cf. Sílvia Fiúza, coord., Autores: histórias da teledramaturgia.

(24) Expressão com que a imprensa passou a se referir ao período mais violento de repressão imposta pelos governos militares, a publicação da Lei de Segurança Nacional em 1969 representa o marco inicial dessa época. Para um detalhamento maior das medidas de exceção adotadas nesse período remetemos a Boris Fausto, História concisa do Brasil, p. 269-282.

(25) Os amigos assistem a cenas gravadas supostamente em VHS do réveillon de 1982 em Paraty e a cenas que mostram o retorno dos amigos que foram exilados durante o regime militar.

(26) Em nossa pesquisa, a discussão em torno da questão da constituição ontológica do ser social tem como ponto de partida o apropriar-se da linguagem como dimensão de aquisição da condição humana (Bakhtin, 2002)

(27) Cf. Eni Orlandi, Análise de discurso: princípios e procedimentos.

\section{Mini Currículo :}

Professora doutora da Escola de Comunicações e Artes da Universidade de São Paulo. 